\title{
Congestive heart failure in subjects with thyrotoxicosis in a black community
}

\author{
This article was published in the following Dove Press journal: \\ Vascular Health and Risk Management \\ 2 July 2010 \\ Number of times this article has been viewed
}

\section{R C Anakwue \\ B J C Onwubere \\ B C Anisiuba \\ $\checkmark$ O Ikeh \\ A Mbah \\ SO Ike}

Department of Medicine, College of Medicine, University of Nigeria Enugu Campus
Correspondence: R C Anakwue Departments of Medicine and Pharmacology and Therapeutics, College of Medicine, University of Nigeria Enugu Campus

Tel 08033343044

Emaildranakwue@yahoo.com
Introduction: Thyroid hormone has profound effects on a number of metabolic processes in virtually all tissues but the cardiovascular manifestations are prominent usually creating a hyperdynamic circulatory state. Thyrotoxicosis is not a common cause of congestive heart failure among black communities.

Objectives: To determine the hospital prevalence, clinical characteristics and echocardiographic findings in patients with thyrotoxicosis who present with congestive heart failure (CCF) in the eastern part of Nigeria.

Subjects and methods: A total of 50 subjects aged 15 years and above who were diagnosed as thyrotoxic following clinical and thyroid function tests were consecutively recruited. Fifty age- and sex-matched controls with no clinical or biochemical evidence of thyrotoxicosis and no comorbidities were used as controls. Two-dimensional echocardiography was carried out on all the subjects. CCF was determined clinically and echocardiographically.

Results: Eight patients ( 5 females and 3 males) out of a total of 50 thyrotoxic patients presented with congestive heart failure.

Conclusion: The study revealed that congestive heart failure can occur in thyrotoxicosis in spite of the associated hyperdynamic condition. The underlying mechanism may include direct damage by autoimmune myocarditis, congestive circulation secondary to excess sodium, and fluid retention.

Keywords: thyrotoxicosis, congestive heart failure, echocardiography, black community

\section{Introduction}

Thyroid hormone has profound effects on a number of metabolic processes in virtually all tissues with the cardiovascular manifestations most prominent. Thyrotoxicosis creates a hyperdynamic circulatory state because of a marked fall in peripheral vascular resistance and associated increase in venous return, increased total blood volume, increased cardiac contractility and heart rate. In spite of the increased cardiac contractile state, congestive heart failure with reduced fractional shortening and ejection fraction still occurs in thyrotoxicosis.

Congestive heart failure in thyrotoxicosis may present with normal or reduced left ventricular systolic function and dilated heart. This may result from a combination of hypervolemic burden, tachyarrhythmias, congestive circulation secondary to excess sodium and fluid retention related to hyperthyroidism and secondary autoimmune myocarditis related to Graves' disease. ${ }^{1}$

Thyrotoxicosis is a rare cause of heart failure and there are very few echocardiographic reports on thyrotoxicosis presenting as congestive heart failure in Nigeria. Kolawole et $\mathrm{al}^{2}$ studied 50 cases of thyrotoxicosis in Ile-ife, western Nigeria and 
reported that 7 patients $(14 \%)$ had congestive heart failure. Danbauchi et $\mathrm{al}^{3}$ in Zaria, northern Nigeria reported 11 cases out of 122 thyrotoxicosis patients who had clinical symptoms and signs of heart failure. The authors are not aware of any echocardiographic study on individuals with thyrotoxicosis that has been done in the eastern part of Nigeria, comprising 9 states out of the 36 states of Nigeria. This geographical location embraces about 40 million of the 150 million population of Nigeria.

The purpose of this study was to determine the hospital prevalence, clinical characteristics and echocardiographic findings in patients with thyrotoxicosis who present with congestive heart failure in the eastern part of Nigeria.

\section{Methods}

We studied 50 patients who were aged 15 years or older, of both sexes and diagnosed of thyrotoxicosis in the medical out patients unit of the University of Nigeria Teaching Hospital (UNTH) Enugu, following clinical and thyroid function tests. Thyrotoxic patients were recruited consecutively as they presented in the medical outpatients unit over a one year period. Informed consent was obtained from all the subjects. The Ethical committee of UNTH approved the study.

Patients who were found to be in heart failure following clinical assessment which demonstrated congestive symptoms: breathlessness, paroxysmal nocturnal dyspnea, orthopnea, coughing and leg swelling were identified and recruited into the study. Thyroid function tests were done with kits from Syntron Bioresearch Inc USA. ${ }^{4}$ The Syntron kits have the following intra-assay coefficient of variation: serum-free tri-iodothyronine (T3) - (6.8\%), thyroid-stimulating hormone of (TSH) - (4.3\%), total free tri-iodothyronine (T3) - $(4.4 \%)$, total tetraiodothyronine (T4) - (7.2\%). ${ }^{4}$ Comparison between Syntron kit and Abbot Kit showed a correlation coefficient of $0.09869 .{ }^{4}$ All the patients had electrocardiography and transthoracic echocardiography done with Sonos 2000 Hewlett Packard machine. Two-dimensional echocardiographic examinations were performed in all subjects with $3.5 \mathrm{MHz}$ transducer according to the recommendations of the American Society of Echocardiography. ${ }^{5}$

The following were excluded from the study: patients who had pre-existing hypertension, diabetes mellitus, anemia, coronary artery disease, exposure to illicit drugs, herbal or any cardiotoxic agents. All pregnant women were also excluded from the study.

Fifty age- and sex-matched controls with no clinical or biochemical evidence of thyrotoxicosis and no comorbidities were included.

\section{Definitions}

The diagnosis of thyrotoxicosis was established in the presence of a serum free $\mathrm{T} 3>4.2 \mathrm{pg} / \mathrm{L}$ and a concomitant suppressed TSH of $<0.5 \mu \mathrm{U} / \mathrm{mL}$.

Left ventricular systolic dysfunction was defined by any of the following: (i) left ventricular ejection fraction (LVEF) $<50 \%$, (ii) fractional shortening (FS) $<18 \%$, (iii) cardiac index $<2.8 \mathrm{~L} / \mathrm{min} / \mathrm{m}^{2}$, (iv) cardiac output $<4 \mathrm{~L} / \mathrm{min}$, (v) mean velocity of circumferential fiber shortening $<1.02 \mathrm{circ} / \mathrm{sec}$, and (vi) peak aortic systolic velocity $<72 \mathrm{~cm} / \mathrm{sec}$.

Dilated thyrotoxic heart muscle disease was defined as (i) end diastolic diameter $>6.0 \mathrm{~cm}$, (ii) end systolic diameter $>2.5 \mathrm{~cm}$, (iii) $\mathrm{LVEF}<50 \%$, and (iv) $\mathrm{FS}<18 \%$. ${ }^{1,5}$

\section{Statistical analysis}

Continuous variables were expressed as mean \pm 1 standard error of mean (SEM). Statistical comparisons were performed using Student's $t$-test. Calculations were performed using SPSS software (SPSS Inc., Chicago, IL) $P<0.05$ was considered significant.

\section{Results Demographic characteristics}

All the patients were black and came from the eastern part of Nigeria. Eight patients - (16\%) (consisting of 5 females and 3 males) out of a total number of 50 thyrotoxic patients presented with congestive heart failure. The patients were predominantly Igbos, with only one from Efik tribe in Akwa Ibom State. Their mean age compared with control was not significantly different. Their mean weight was $56 \mathrm{~kg}( \pm 4.1)$ : range $52-72 \mathrm{~kg}$. This is significantly lower than the weight $65 \mathrm{~kg}( \pm 5.7)$ : range $64-78 \mathrm{~kg}$ of the controls $(P<0.05)$ (Table 1).

\section{Clinical characteristics and thyroid function test}

The 8 patients who had congestive heart failure presented with symptoms of congestion, dyspnea, coughing and leg swelling, as well symptoms suggestive of thyrotoxicosis. These included palpitation, heat intolerance, tremulousness, increased sweating. They all had Graves' disease. The mean heart rate was significantly higher in the thyrotoxicosis patients than in the control (102 bpm vs $78 \mathrm{bpm}, P<0.01)$ whereas there were no significant differences in the mean systolic blood pressure and the mean diastolic blood pressure between the test group and control. 
Table I Clinical, anthropometric data and thyroid function of patients and controls

\begin{tabular}{|c|c|c|c|c|}
\hline Parameters & $\begin{array}{l}\text { Thyrotoxicosis } \\
\text { Patients: Mean } \\
( \pm \text { SD) }\end{array}$ & $\begin{array}{l}\text { Control: } \\
\text { Mean } \\
( \pm \text { SD) }\end{array}$ & $\begin{array}{l}t \text {-test } \\
\text { value }\end{array}$ & $\begin{array}{l}P \text { - } \\
\text { value }\end{array}$ \\
\hline Age & $44(3.1)$ & $43.5(5.2)$ & 0.85 & $>0.05$ \\
\hline Weight (kg) & $56.0(5.5)$ & $65(7.6)$ & -6.4 & $<0.05^{*}$ \\
\hline Height (meters) & $159.5(6.8)$ & $160.8(I 5.9)$ & 1.35 & $>0.05$ \\
\hline $\begin{array}{l}\text { Body surface } \\
\text { area }\left(\mathrm{m}^{2}\right)\end{array}$ & $1.2(2.4)$ & $1.6(0.17)$ & 1.85 & $<0.5^{*}$ \\
\hline $\begin{array}{l}\text { Body mass } \\
\text { Index }\left(\mathrm{kg} / \mathrm{m}^{2}\right)\end{array}$ & $22.04(6.4)$ & $25.09(5.4)$ & -1.87 & $<0.05^{*}$ \\
\hline Pulse (beats/min) & $102(11.9)$ & $78(5.2)$ & 8.57 & $<0.01^{*}$ \\
\hline $\begin{array}{l}\text { Systolic Blood } \\
\text { Pressure }(\mathrm{mmHg})\end{array}$ & $124.2(12.5)$ & $122.9(2.8)$ & 0.12 & $>0.05$ \\
\hline $\begin{array}{l}\text { Diastolic Blood } \\
\text { Pressure(mmHg) }\end{array}$ & 75 (II.4) & 79.1 (6.5) & 1.5 & $>0.05$ \\
\hline $\mathrm{TSH}(\mu \mathrm{u} / \mathrm{mL})$ & $0.28(0.1)$ & $2.3(1.5)$ & 20.6 & $<0.01^{*}$ \\
\hline Total T3 (ng/mL) & $4.7(3.9)$ & I.5 (I.I) & 2.5 & $<0.0 \mathrm{I}^{*}$ \\
\hline Total T4 (ug/mL) & $173(4.2)$ & $56(2.1)$ & 20.6 & $<0.0 \mathrm{I}^{*}$ \\
\hline Free T3 (pg/mL) & $5.9(0.9)$ & $2.3(0.3)$ & 11.9 & $<0.01^{*}$ \\
\hline
\end{tabular}

Note: "Represents significant value.

Abbreviations: $\mathrm{T} 3$, tri-iodothyronine; $\mathrm{T} 4$, tetraiodothyronine; $\mathrm{TSH}$, thyroid stimulating hormone.

The mean serum T3 was $5.9(0.09) \mathrm{ng} / \mathrm{mL}$ and this was significantly higher than a mean of $2.3(0.4) \mathrm{ng} / \mathrm{mL}$ in the control $(P<0.01)$. The mean serum TSH was significantly lower in the thyrotoxicosis patients than in the control $(P<0.01)$ (Table 1).

\section{Echocardiographic findings}

Echocardiography showed that 5 patients had ejection fraction (LVEF) of $<50 \%$.

Fractional shortening (FS) of $<18 \%$ was found in 6 patients $(12 \%)$, cardiac index of $<2.8 \mathrm{~L} / \mathrm{min} / \mathrm{m}^{2}$ in 5 patients, cardiac output of $<5 \mathrm{~L}$ in 5 patients $(10 \%)$, velocity of circumferential fiber shortening of $<1.02 \mathrm{circ} / \mathrm{sec}$ in 5 patients (10\%), aortic maximum velocity of $<72 \mathrm{~cm} / \mathrm{sec}$ in 5 patients $(10 \%)$. Three of the thyrotoxicosis patients in heart failure clinically, had normal LVEF and FS (50\%-75\%). This is depicted in Figure 1. Thyrotoxicosis patients without heart failure who had normal systolic function (31 patients - 62\%) and enhanced systolic function (11 patients $-22 \%$ ) are also shown in Figure 1. Thyrotoxicosis patients in heart failure had significantly lower systolic function than control (Table 2).

Echocardiography showed that the 5 patients who had LVEF of $<50 \%$ also had dilatation of other chambers of the heart. A two-dimensional echogram showing dilated heart chambers in thyrotoxicosis is shown in Figure 2.

No echocardiographic findings indicating abnormal systolic dysfunction were found in the control group.
Electrocardiography showed that two out of the five patients with LVEF of $<50 \%$ were in atrial fibrillation.

\section{Discussion}

This study has shown that congestive heart failure occurs in thyrotoxicosis patients in eastern Nigeria. In spite of the hyperdynamic state found in thyrotoxicosis, low output heart failure with dilated hearts can occur. Is this a true thyrotoxic heart muscle disease or secondary to hemodynamic conditions found in thyrotoxicosis?

No definitive answer has been given to this question. However studies have demonstrated the presence of fibroblast infiltration and degenerative changes as well as TSH-receptor (TSH-R) in human heart in Graves' disease. TSH-R mRNA was identified in the human heart using the reverse transcriptase polymerase chain reaction and DNA sequencing. ${ }^{\text {? }}$ Myocardial damage evidenced by III-labeled monoclonal antimyosin antibodies have also occurred in hyperthyroidism with heart failure and both myocardial damage, and left ventricular dysfunction disappeared after antithyroid therapy. ${ }^{8}$

There are hemodynamic conditions in thyrotoxicosis that may increase cardiac load and stress and predispose to failure. The increased cardiac preload which occurs in thyrotoxicosis may be due to peripheral vasodilatation, activation of the renin-angiotensin-aldosterone system and upregulation of the erythropoietin secretion and red blood cell mass, which in turn will increase total blood volume. ${ }^{1}$

The hospital-based studies by Kolawole et $\mathrm{al}^{2}$ and Danbauchi et $\mathrm{al}^{3}$ showed that $14 \%$ and $8 \%$ of their patients had heart failure, respectively. These figures are lower than the $16 \%$ in our index study. This may possibly be due to the fact that our cohort of patients were pulled from nearby hospitals and late presentation could be largely contributory. It is instructive to know that more of the patients in this study had Graves' disease (100\%), compared to only $52 \%$ of Kolawole et $\mathrm{al}^{2}$ patients. Atrial fibrillation, which contributes to heart failure in thyrotoxicosis, was found in $4 \%$ in Ife $^{2}$ and $2 \%$ in the Zaria ${ }^{3}$ studies respectively. These figures are comparable with $4 \%$ found in this study.

All the 61 thyrotoxicosis patients studied by Niakara et $\mathrm{al}^{9}$ in Burkina Faso had thyrotoxic heart disease, so it is not surprising that $80.3 \%$ of them had heart failure and $24.3 \%$ had atrial fibrillation. However, only $54.3 \%$ of them had Graves' disease.

In the study by Siu et al ${ }^{1}$ in China, $5.8 \%$ of their patients had heart failure. In their study there was no significant difference in the incidence of Graves' disease between patients with and without left ventricular systolic dysfunction. 


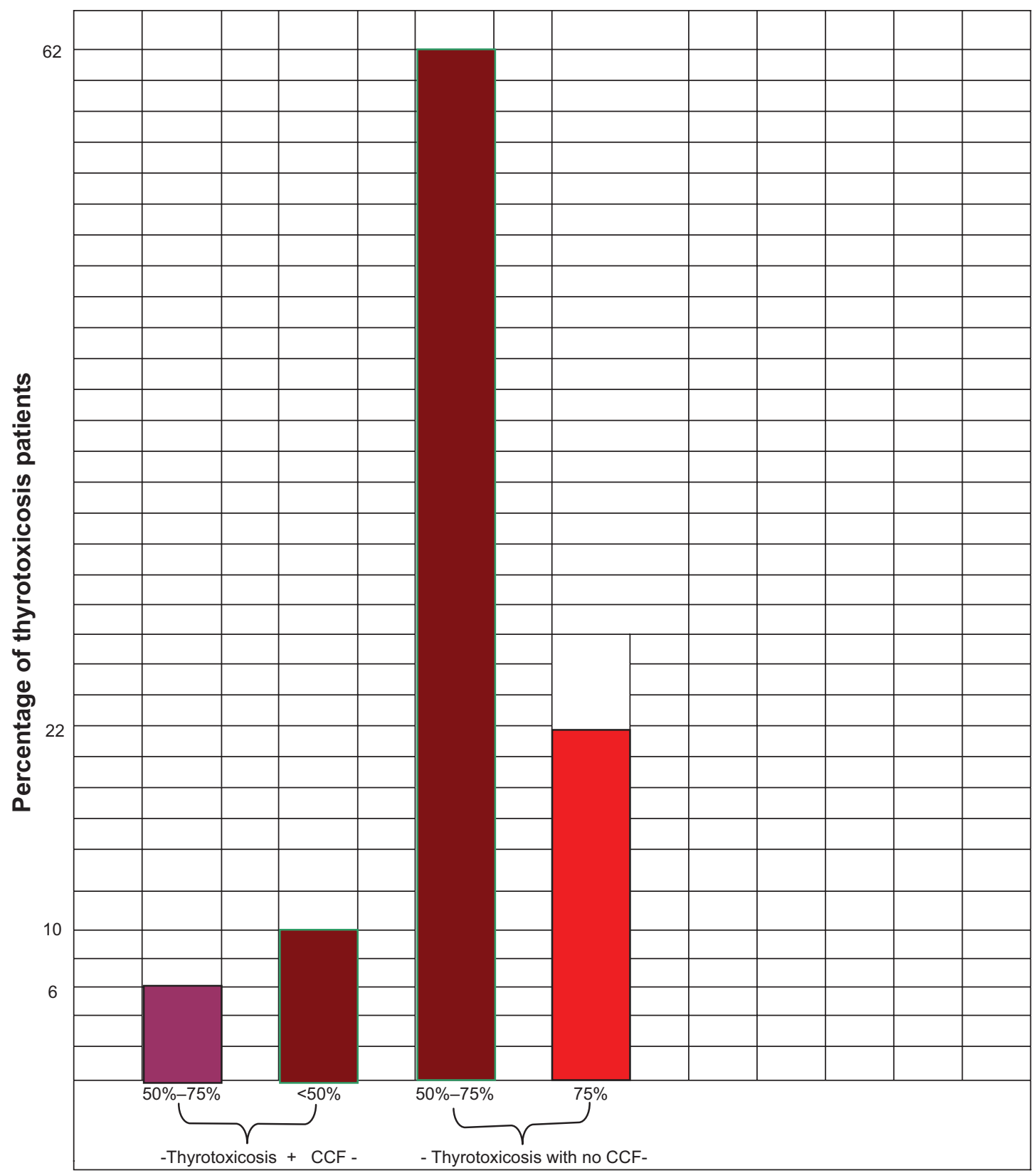

Left ventricular ejection fraction

Figure I Bar chart comparing proportions of thyrotoxicosis patients with and without congestive heart failure using left ventricular ejection fraction as a systolic parameter. $*<50 \%=$ systolic dysfunction, $50 \%-75 \%=$ normal systolic function, $>75 \%=$ enhanced systolic function.

Table 2 Comparison of proportions of left ventricular systolic dysfunction parameters of thyrotoxicosis patients and control

\begin{tabular}{llllc}
\hline Parameters & $\begin{array}{l}\text { Proportions found in } \\
\text { Thyrotoxicosis Patients } \mathbf{P}_{\mathbf{T}}\end{array}$ & $\begin{array}{l}\text { Proportions found } \\
\text { in Control } \mathbf{P}_{\mathrm{C}}\end{array}$ & t-test value & $\boldsymbol{P}_{\text {-value }}$ \\
\hline LVER $<50 \%$ & 0.10 & 0.00 & 2.05 & $<0.05^{*}$ \\
FS $<18 \%$ & 0.12 & 0.00 & 2.35 & $<0.05^{*}$ \\
Cardiac index $<2.8 \mathrm{~L} / \mathrm{min} / \mathrm{m}^{2}$ & 0.10 & 0.02 & 2.52 & $<0.05^{*}$ \\
Cardiac output $<4 \mathrm{~L}$ & 0.10 & 0.02 & 2.1 & $<0.05^{*}$ \\
Peak aortic systolic velocity $<72 \mathrm{~cm} / \mathrm{s}$ & 0.12 & 0.00 & 2.30 & $<0.05^{*}$ \\
VCF(circumferences/second) $<1.02$ & 0.10 & 0.00 & 2.35 & $<0.05^{*}$ \\
\hline
\end{tabular}

Abbreviations: FS, fractional shortening; VCF, velocity of circumferential fiber shortening; LVEFR, Left ventricular ejection fraction. 


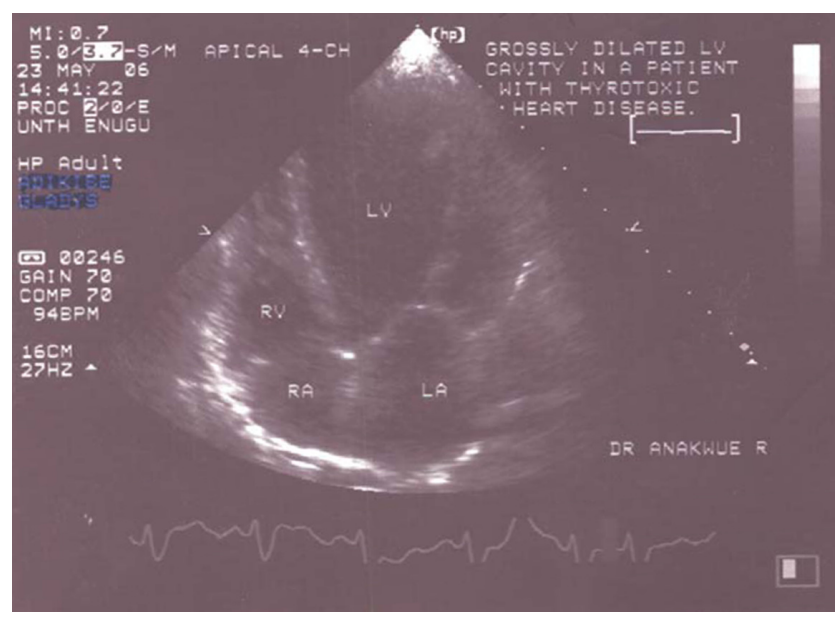

Figure 2 Two-dimensional echocardiogram showing dilated heart chambers.

Dilated hearts, as shown in Figure 2, have been noted in other studies to be associated with reduced LVEF. Interestingly, restoring normal levels of thyroid hormone often reverses the dilation and dysfunction, which makes thyrotoxic heart failure a curable disease.

\section{Conclusion}

Heart failure can occur in thyrotoxicosis in spite of the associated hyperdynamic condition. The underlying mechanism may include direct damage by autoimmune myocarditis, congestive circulation secondary to excess sodium and fluid retention related to hyperthyroidism or diastolic heart failure triggered by sustained tachycardia and or atrial fibrillation. ${ }^{10}$ This study has demonstrated that heart failure in thyrotoxicosis may be accompanied with normal or low cardiac output state.

\section{Disclosure}

The authors declare no conflicts of interest in this work.

\section{References}

1. Siu C, Yeung C, Lau C, Kung AWC, Tse H. Incidence, clinical characteristics and outcome of congestive heart failure as the initial presentation in patients with hyperthyroidism. Heart. 2007;93: 483-487.

2. Kolawole BA, Balogun MO, Akinsola A. Thyrotoxicosis and heart - a review of the literature. Nigerian Journal of Medicine. 2001;16(2):50-54.

3. Danbauchi SS, Anumah FE, Alhassan MA, et al. Thyrocardiac disease in Zaria: clinical and echocardiographic characteristics. Echocardiography Journal. 2004;2:1-5.

4. Syntron Bioresearch Inc. Laboratory Instruction Manuscript. Carlsbad, CA, USA. 1998; Catalog Numbers, 1006-2210.

5. Schiller MB. Recommendations for quantification of the left ventricle by two-dimensional echocardiography. J Am Soc Echocardiography. 1989;2:362-364.

6. Rijsterborgh H, Romdoni R, Vletter W, Bom N, Roselandt J. Reference ranges of left ventricular cross-sectional echocardiographic measurements in adult men. J Am Soc Echocardiography. 1989;2: 415-417.

7. Koshiyama H, Sellitti DF, Akamizu T, Doi SQ, Takeuchi Y, Iuoue D, et al. Cardiomyopathy associated with Graves' disease. Clin Endocr. 1996;1:111-116.

8. Marti V, Ballester M, Obrador D, Moya C, Carrio I, Pons-Liado G. Active myocardial damage in hyperthyroidism. A concurrent mechanism of hear failure reversed by treatment. Eur Heart. 1995;1014-1016.

9. Niakara A, Bama A, Nebie LVA. Signs and outcome of 61 cases of thyrotoxic heart disease. Trop Cardiol. 2004;30: 118:24-27.

10. Osman F, Daykin J, Sheppard MC, Gammage MD, Frankln JA. Atrial fibrillation predicts mortality in thyrotoxicosis. British Endocrinology Society Meeting 2002. Bioscientifica. 2002;275-278.
Vascular Health and Risk Management

\section{Publish your work in this journal}

Vascular Health and Risk Management is an international, peerreviewed journal of therapeutics and risk management, focusing on concise rapid reporting of clinical studies on the processes involved in the maintenance of vascular health; the monitoring, prevention and treatment of vascular disease and its sequelae; and the involvement of

\section{Dovepress}

metabolic disorders, particularly diabetes. This journal is indexed on PubMed Central and MedLine. The manuscript management system is completely online and includes a very quick and fair peer-review system, which is all easy to use. Visit http://www.dovepress.com/ testimonials.php to read real quotes from published authors. 